\section{Frontotemporal dementia in amyotrophic lateral sclerosis: from rarity to reality?}

\author{
Marco Orsini, ${ }^{1}$ Ana Carolina Andorinho \\ de Freitas Ferreira, ${ }^{2}$ Osvaldo J.M. \\ Nascimento, ${ }^{2}$ Jano Alves de Souza, ${ }^{2}$ \\ Thaís Nascimento Magalhães, ${ }^{2}$ \\ Anna Carolina Damm de Assis, ${ }^{2}$ Larissa \\ Kozow Westin, ${ }^{2}$ Bruno Pessoa, ${ }^{2}$ Acary \\ Bulle Oliveira, ${ }^{3}$ Rossano Fiorelli, 4 \\ Marcos R.G. de Freitas, 2 \\ Juliana Bittencourt, ${ }^{1}$ Stenio Fiorelli, ${ }^{4}$ \\ Maria Fernanda Freitas Ferreira Moreira, 5 \\ Pedro Ribeiro ${ }^{1}$ \\ ${ }^{1}$ Brain Mapping Laboratory and \\ Electroencephalogram, Federal University \\ of Rio de Janeiro and Severino Sombra \\ University Center, Vassouras, RJ; \\ ${ }^{2}$ Antonio Pedro University Hospital - \\ HUAP - Federal Fluminense University, \\ Niterói; ${ }^{3}$ Department of Neurology, \\ Federal University of São Paulo;. \\ 4Department of Neurology, Masters \\ Program (Neurology) - UNIRIO; ${ }^{5}$ Estácio \\ de Sá University, School of Medicine, Rio \\ de Janeiro, Brazil
}

Amyotrophic lateral sclerosis (ALS) was initially described in 1869 by Jean-Martin Charcot. ${ }^{1} \mathrm{ALS}$ is a progressive neurodegenerative disease that affects motoneurons in the cortex, medulla, and spinal cord.2,3 The lesion of Upper Motor Neuron (UMN) generates spasticity, weakness, and hyperreflexia. The affection of Lower Motor Neuron (LMN) justifies the observed fasciculation, fatigue and weakness. In the presence of bulbar dysfunction, it is seen dysarthria, dysphagia, weakness and tongue fasciculations.4,5 Commonly, it leads to death by respiratory failure a few years after onset of first symptoms. ${ }^{6}$

ALS is a multifactorial disorder, which involves both glial cells and neurons. According to Moura MC and colleagues (2016), the main known pathogenesis mechanisms include oxidative stress with damage to RNA, mitochondrial dysfunction, impairment of axonal transport and glutamate excitotoxicity. There are also described: protein aggregation, endoplasmic reticulum (ER) stress, abnormal RNA processing, neuroinflammation and excitability of peripheral axons. ${ }^{7}$

Genetic and environmental factors may play an important role, influencing the susceptibility to ALS due the interactions between them and epigenetics effects, which leads to a phenotypic individuality. Approximately $90-95 \%$ of patients have sporadic ALS, and the remaining $5-10 \%$ of them has familial ALS. ${ }^{8}$

According to El Escorial and Airlie House
Criteria, a definitive diagnosis of ALS requires the following features: clinical, electrophysiological or neuropathological examination that identifies LMN degeneration. By clinical examination of UMN, degeneration and progression of the motor syndrome within a region or to other ones are necessary. Besides, it is fundamental to rule out possible imaging, electrophysiological or pathological evidence of another disease that may justify clinical signs of UMN or LMN deterioration.9,10

The neurophysiological investigation should include nerve conduction studies, electromyography, and, less commonly, transcranial magnetic stimulation. ${ }^{11}$ Electromyography and nerve conduction are useful for the identification of LMN loss and illustrates LMN loss (i.e.; fibrillation potentials, positive sharp waves, and chronic neurogenic changes).5,12

Regarding neuroimaging, some of them have been used to aid in the diagnosis of ALS, but its success is still variable. Studies with magnetic resonance imaging (MRI) show motor system atrophy, especially in pyramidal tract. At a more advanced stage, changes might be seen already in motor cortex. ${ }^{13}$ Diffusion tensor imaging (DTI), also known as tractography, arises as a promising method. Considering its higher sensitivity to evaluate microstructural function and integrity of white matter fibers, DTI would evince the early damage of UMN. Those signs might be subtle and hamper the definitive diagnosis of ALS. However, since the current findings are nonspecific, and imaging is more useful to discard diseases that mimic ALS, MRI studies have not been established as a routine use yet. ${ }^{14,15}$

The relationship between ALS and dementia dates back in 1950 when it was linked to aphasia and Pick's disease.16,17 In 1960s, the first studies describing the association of ALS and Parkinsonism-Dementia Complex (PDC) were published, referring to the indigenous Chamorro population, native inhabitants of Guam. ${ }^{18,19}$ The higher incidence of the disease among patients' relatives compared to control ones launched the basis of the familiar aspect of ALS+PDC. ${ }^{20}$ Forty years after the former reports, greater risk persisted, being the new cases among patients' relatives even in greater number than expected. ${ }^{21}$ Furthermore, tau pathological features found both in cases of ALS and ALS+PDC patients seal the relation between ALS and dementia development. ${ }^{22}$

Following this reasoning, the overlap of ALS and Frontotemporal Dementia (now referred to as frontotemporal lobar degeneration FTLD) was also registered through punctual and prospective analysis of FTLD patients with no known diagnosis of ALS or family history of ALS.22 It is worth remembering that ubiquitinpositive neuronal inclusions have been found both in some cases of ALS and in FTLD related to motor neuron disease, whose findings tends
Correspondence: Marco Orsini, Brain Mapping Laboratory and Electroencephalogram, Federal University of Rio de Janeiro, Av. Pedro Calmon, 550 - Cidade Universitária, Rio de Janeiro - RJ, 21941-901, Brazil.

E-mail: orsinimarco@hotmail.com

Key words: Frontotemporal dementia; Amyotrophic lateral sclerosis; Neurodegenerative disease.

Contributions: the authors contributed equally.

Conflict of interest: the authors declare no potential conflict of interest.

Received for publication: 8 April 2016.

Accepted for publication: 6 June 2016 .

This work is licensed under a Creative Commons Attribution NonCommercial 4.0 License (CC BYNC 4.0).

(C) Copyright M. Orsini et al., 2016

Licensee PAGEPress, Italy

Neurology International 2016; 8:6534

doi:10.4081/ni.2016.6534

to arise promptly, endorsing the hypothesis of a spectrum binding both diseases.23,24 TAR DNA-binding protein of $43 \mathrm{kDa}$ (TDP-43), a nuclear factor that works in transcriptional expression and exon skipping, was proved to be present in neuronal cytoplasmic inclusions and dystrophic neuritis in the hippocampal region and temporal cortex of FTLD-Motor Neuron Disease (MND) and FTLD-MND-type cases. These inclusions and neuritis were comparable to that of ubiquitin-positive inclusions and neuritis. In the spinal cord of the ALS and FTLD-MND cases, skein-like inclusions were positive for ubiquitin and also for polyclonal and monoclonal antibodies to TDP43.24 Some mutations involving TDP-43 have been identified, for instance, the missense mutation A315T within a highly conserved region of exon 6 with an autosomal dominant pattern of inheritance. ${ }^{25}$ Recently, this mutation was demonstrated to induce ER stressmediated apoptosis besides autophagy, as a self-protection to neuronal toxicity in vitro. ${ }^{26}$

In 2006, Morita and colleagues issued the results of a genome-wide linkage analysis of this association. They studied a four-generation, 50-member Scandinavian family, whose five individuals were diagnosed with ALS and nine with FTD. It was identified a new locus for ALS/FTD: chromosome 9p21.3-p13.3.27 Still, DeJesus-Hernandez and colleagues (2011) detected the polymorphic GGGGCC hexanucleotide repeat in a noncoding region of chromosome 9 open reading frame 72 (C90RF72) as the Chromosome 9p21-Linked familial FTD/ALS.28 
This expansion comprises an intronic region of C9orf72 between non-coding exons 1a and $1 \mathrm{~b}$, which are alternatively spliced to generate three RNA variants. The hexanucleotide repeat expansion forms RNA is believed to sequester RNA-Binding Proteins (RBPs) and impair their function in RNA processing. The repeat expansion also undergoes translation that results in dipeptide repeat proteins (DPRs), which form inclusions in CNS. Finally, it induces the mislocalization and aggregation of TAR DNA-binding protein 43 (TDP-43). ${ }^{29}$

Byrne and colleagues (2012) verified that their sample of 39 ALS patients with more than 23 hexanucleotide repetitions represented a sub phenotype. This one was characterized by a lower age of onset, cognitive and behavioral impairment, specific neuroimaging changes (substantial non-motor cortex changes on high-resolution 3T structural MRI and reduced grey-matter volume), a robust family history of neurodegeneration and reduced survival. The repeat expansion was absent in patients who had sporadic ALS and no behavioral abnormalities and was present in high proportion in ALS patients with a predominance of executive cognitive impairment and behavioral change. 30 However, it must be remembered that repeat expansion was found both in familial as sporadic cases. Finish cohort of 402 ALS cases and 478 controls registered hexanucleotide repeat expanded in 113 (28.1\%) patients, being calculated as $46.4 \%$ of familial and $21.0 \%$ of the sporadic cases. ${ }^{31}$ Recent study among Italian patients confirmed the primary role of C9orf72 in increasing the risk of FTLD in ALS patients but also showed the importance of APOE 2 allele to a lesser extent to this relation. 32

Radford and colleagues (2015) summarize the pathological protein inclusion that reinforces the continuum idea that bound ALS to FTLD. At one end, there is SOD1 inclusion, exclusively of ALS and positive in $2 \%$ of the cases. At the other end, there is Tau inclusion, exclusively of FTLD and positive in $40-45 \%$ of the cases; in the middle, there are TDP-43 inclusions, positive in $90-95 \%$ of ALS and in $45-50 \%$ of FTLD cases. It is highlighted the disturbance of microglial in both diseases. Loss of TREM2 protein function (exclusively expressed by microglia in the CNS) and mutations of progranulin (GRN, a neuroinflammatory modulator expressed by neurons and microglia) lead to dysfunctional microglial phagocytosis and altered inflammatory responses. They are implicated as risk factors for ALS, FTD, and Alzheimer's disease. ${ }^{33}$

Another important feature is the image study. The association ALS-FTD seemed to express higher atrophy ratings compared to ALS patients for the motor cortex, anterior cingulate, temporal and occipital lobes and a sta- tistical trend for the orbitofrontal cortex. ${ }^{34,35}$ DTI shows reduced white matter integrity relative in frontal and temporal regions when comparing to healthy older adults. Positron emission tomography (PET) and functional MRI (fMRI) reveals alterations in brain function and connectivity during executive task but also in resting state. Moreover, mutation in chromosome 9 is related to a greater frontal lobe thalamic, temporal lobe, insular, and posterior cortical atrophy than other mutations. ${ }^{35}$ Thus employment of this MRI rating scale would serve as a complement clinical diagnostics of patients in the ALS-FTD continuum.

Nowadays, it would be a restrained practice to consider only the motor aspects of ALS, even though it is a widespread clinical and electrophysiological disease. Cognitive impairment may be already seen in the absence of dementia. Moreover, the association with dementia diagnosis has already been reported many decades ago. It should draw our attention for the atypical characteristic that preponderates in these cases of dementia: in the isolated indigenous population of Guam, the Parkinsonism-Dementia Complex became target of study among ALS patients. However, in general population, the fronto-temporal lobar degeneration turned into a prevalent association described in ALS cases.

The more we know about the possible symptoms and complementary assessment related to ALS, the better is the standard of care from doctors and health practitioners for this complex disease. Concerning the FTLD overlap, the researches have been advanced, allowing the discovery of special markers, as TDP-43 mutation and Cr9orf72 expansion. These mutations have a significant prevalence value in ALS, which might be useful as corroborative item in the diagnosis. Themolecular subtract also justifies the genetic counseling, especially in the at-risk group (i.e., patients with evidence of cognitive and behavioral impairment or a family history of neurodegenerative disease). Fortunately, once there is an individualized molecular marker, many opportunities are created to the developing of new treatments, more target specific and possibly, more effective.

\section{References}

1. Zarei S, Carr K, Reiley L, et al. A comprehensive review of amyotrophic lateral sclerosis. Surg Neurol Int 2015;6:171.

2. Shen D, Cui L, Cui B, et al. A systematic review and meta-analysis of the functional MRI investigation of motor neuron disease. Front Neurol 2015;6:246.

3. Eisen A. Amyotrophic lateral sclerosis: a review. BCMJ 2002;44:362-6.

4. Riancho J, et al. [¿Por qué degeneran las motoneuronas? Actualización en la patogenia de la esclerosis lateral amiotrófica.] Neurologia 2016. [Epub ahead of print] [Article in Spanish]

5. Matthew CK, Steve V, Benjamin CC, et al. Amyotrophic lateral sclerosis. Lancet 2011;377:942-55.

6. Orsini M, Oliveira AB, Nascimento OJM, et al. Amyotrophic lateral sclerosis: new perpectives and update. Neurol Int 2015;7:5885.

7. Moura MC, Novaes MRCG, Zago YSSP, et al. Efficacy of stem cell therapy in amyotrophic lateral sclerosis: a systematic review and meta-analysis. J Clin Med Res 2016;8:317-24.

8. Zou ZY, Liu CY, Che CH, Huang HP. Toward precision medicine in amyotrophic lateral sclerosis. Ann Transl Med 2016;4:27.

9. Hardiman 0, van den Berg LH, Kiernan MC. Clinical diagnosis and management of amyotrophic lateral sclerosis. Nat Rev Neurol 2011;7:639-49.

10. Beghi E, Balzarini C, Bogliun G, et al. Reliability of the El Escorial diagnostic criteria for amyotrophic lateral sclerosis. Neuroepidemiology 2002;21:265-70.

11. Sutedja NA, Veldink JH, Fischer K, et al. Exposure to chemicals and metals and risk of amyotrophic lateral sclerosis: a systematic review. Amyotroph Lateral Scler 2009;10:302-9.

12. de Carvalho M, Dengler R, Eisen A, et al. Electrodiagnostic criteria for diagnosis of ALS. Clin Neurophysiol 2008;119:497-503.

13. Hofmann E. The corticospinal tract in amyotrophic lateral sclerosis: an MRI study. Neuroradiology 1998;40:71-5.

14. Yin H, Lim CCT. Combined MR spectroscopic imaging and diffusion tensor MRI visualizes corticospinal tract degeneration in amyotrophic lateral sclerosis. J Neurol 2004;251:1249-54.

15. Garcia LN, Silva AV, Carrete H Jr, et al. [Relação entre degeneração do trato córtico-espinhal através de ressonância magnética e escala funcional (ALSFRS) em pacientes com esclerose lateral amiotrófica.] Arq Neuropsiquiatr 2007;65:869-74. [Article in Portuguese]

16. Michaux L, Sampson M, Harl JM, et al. Development of dementia in two cases of amyotrophic lateral sclerosis with aphasia. Rev Neurol (Paris) 1955;92:357-67.

17. Lechelle P, Buge A, Leroy R. Pick's disease; terminal amyotrophic lateral sclerosis. Bull Mem Soc Med Hop Paris 1954;70: 1090-4.

18. Hirano A, Kurland LT, Krooth RS, et al. Parkinsonism-dementia complex and endemic disease on the island of Guam. I. Clinical features. Brain 1961;84:642-61.

19. Lessell S, Hirano A, Torres J, et al. Parkinsonism-dementia complex: epi- 
demiological considerations in the chamorros of the Mariana Islands and California. Arch Neurol 1962;7:377-85.

20. Plato CC, Reed DM, Elizan TS, et al. Amyotrophic lateral sclerosisParkinsonism-dementia complex of Guam. IV. Familial and genetic investigations. Am J Hum Genet 1967;19:617-32.

21. Plato CC, Galasko D, Garruto RM, et al. ALS and PDC of Guam: forty-year follow-up. Neurology 2002;58:765-73.

22. Lomen-Hoerth C, Anderson T, Miller B. The overlap of amyotrophic lateral sclerosis and frontotemporal dementia. Neurology 2002;59:1077-9.

23. Clarck CM, Forman MS. Frontotemporal lobar degeneration with motor neuron disease: - a clinical and pathological spectrum. Arch Neurol 2006;63:489-90.

24. Arai T, Hasegawa M, Akiyama $\mathrm{H}$, et al. TDP-43 is a component of ubiquitin-positive tau-negative inclusions in frontotemporal lobar degeneration and amyotrophic lateral sclerosis. Biochem Biophys Res Commun 2006;351:602-11.

25. Gitcho MA, Baloh RH, Chakraverty S, et al. TDP-43 A315T mutation in familial motor neuron disease. Ann Neurol 2008;63:535-8.

26. Wang X, Zhou S, Ding X, et al. Activation of ER stress and autophagy induced by TDP43 A315T as pathogenic mechanism and the corresponding histological changes in skin as potential biomarker for ALS with the mutation. Int J Biol Sci 2015;11:11409.

27. Morita M, Al-Chalabi A, Andersen PM. A locus on chromosome 9p confers susceptibility to ALS and frontotemporal dementia. Neurology 2006;66:839-44.

28. DeJesus-Hernandez M, Mackenzie IR, Boeve BF. Expanded GGGGCC hexanucleotide repeat in noncoding region of C90RF72 causes chromosome 9p-linked FTD and ALS. Neuron 2011;72:245-54.

29. Todd TW, Petrucelli L. Insights into the pathogenic mechanisms of Chromosome 9 open reading frame 72 (C9orf72) repeat expansions. J Neurochem 2016. [Epub ahead of print]

30. Byrne S, Elamin M, Bede P, et al. Cognitive and clinical characteristics of patients with amyotrophic lateral sclerosis carrying a C9orf72 repeat expansion: a populationbased cohort study. Lancet Neurol
2012;11:232-40.

31. Renton AE, Majounie E, Waite A, et al. A hexanucleotide repeat expansion in C90RF72 is the cause of chromosome 9p21-linked ALS-FTD. Neuron 2011;72: 257-68.

32. Chiò A, Brunetti M, Barberis M, et al. The role of $\mathrm{APOE}$ in the occurrence of frontotemporal dementia in amyotrophic lateral sclerosis. JAMA Neurol 2016;73:425-30.

33. Radford RA, Morsch M, Rayner SL, et al. The established and emerging roles of astrocytes and microglia in amyotrophic lateral sclerosis and frontotemporal dementia. Front Cell Neurosci 2015;9:414.

34. Ambikairajah A, Devenney E, Flanagan E, et al. A visual MRI atrophy rating scale for the amyotrophic lateral sclerosis-frontotemporal dementia continuum. Amyotroph Lateral Scler Frontotemporal Degener 2014;15:226-34.

35. Trojsi F, Monsurrò MR, Esposito F, Tedeschi G. Widespread structural and functional connectivity changes in amyotrophic lateral sclerosis: insights from advanced neuroimaging research. Neural Plast 2012;2012:473538. 